\title{
ÁCIDOS NAFTÊNICOS NO PETRÓLEO
}

Liliane Dailei Almeida Gruber, Flaviana Cardoso Damasceno, Elina Bastos Caramão e Rosângela Assis Jacques*

Instituto de Química, Universidade Federal do Rio Grande do Sul, Av. Bento Gonçalves, 9500, 91501-970 Porto Alegre - RS, Brasil

Ana Maria Geller

Instituto Federal Sul-rio-grandense, Campus Camaquã, Rua Ana Gonçalves da Silva, 901, 96180-000 Camaquã - RS, Brasil

Maria Cecília Vaz de Campos

Instituto Federal Sul-rio-grandense, Campus Pelotas, Praça Vinte de Setembro, 455, 96015-360 Pelotas - RS, Brasil

Recebido em 22/7/11; aceito em 5/2/12; publicado na web em 15/5/12

\begin{abstract}
NAPHTHENIC ACIDS IN PETROLEUM. Brazilian petroleum is known by its high acidity due to the presence of acidic constituents, especially naphthenic acids (NA). The total characterization of the NA in petrochemical samples has been receiving special attention in research and comprises an analytical challenge, mainly due to the complexity of their mixtures. Gas chromatography with mass detector (GC/MS) is the technique of analysis more used, but recently comprehensive two-dimensional gas chromatography $(\mathrm{GC} \times \mathrm{GC})$ has been used, due to its high resolution, peak capacity and sensitivity. The goal of this article is to discuss the techniques for sample preparation and analysis of NA in petroleum.
\end{abstract}

Keywords: petrochemicals samples; naphthenic acids; characterization of the NA.

\section{INTRODUÇÃO}

Nos últimos anos grande parte das reservas de petróleo descobertas em território brasileiro consiste de óleo pesado de baixo grau API $\left(<20^{\circ}\right)$, alta viscosidade e elevada acidez total. ${ }^{1}$ A Empresa de Petróleo Brasileiro S/A, PETROBRAS, visando viabilizar a comercialização do petróleo vem investindo em programas de pesquisa e desenvolvimento, tais como, PRAVAP (Programa de Recuperação Avançada de Petróleo), PROTER (Programa de Tecnologias Estratégicas de Refino) e PROPES (Programa Tecnológico de Óleos Pesados).

As fontes de óleo cru na América do Sul, incluindo o petróleo brasileiro, estão entre as mais ácidas do mundo. ${ }^{2,3}$ Tal acidez é responsabilizada por muitas dificuldades na utilização desta matéria-prima nas refinarias e no aproveitamento de seus resíduos.

Os ácidos naftênicos (AN) são encontrados, predominantemente, em óleos imaturos, biodegradados, em óleos pesados e águas residuárias geradas no processo de extração do betume. ${ }^{4,5}$ Sua importância é salientada em geoquímica, aplicações comerciais, aspectos ambientais e corrosão. ${ }^{2-6}$

O termo naftênico, correspondente a compostos cíclicos saturados, é usado para todos os tipos de ácidos encontrados em petróleos, mesmo os saturados lineares e os ramificados. ${ }^{2,5,7}$ Os ácidos carboxílicos presentes no petróleo representam um grande problema para o refino e craqueamento do mesmo, devido ao seu efeito corrosivo em linhas de transferência de massa e calor, nas seções de entrada e refluxo de colunas (à pressão atmosférica e a vácuo) e nos condensadores das unidades de destilação das refinarias. ${ }^{5}$ De forma geral, determina-se o teor de ácidos através da titulação com $\mathrm{KOH}$, obtendo-se então o índice ou número de acidez naftênica. Este índice pode ser indicativo de atividade corrosiva da amostra, contudo, nada acrescenta quanto à qualidade do petróleo e à natureza dos ácidos presentes. Para caracterizar estes ácidos, é necessário extraí-los e analisá-los de forma individual., ${ }^{2,5}$

O petróleo é constituído de uma mistura complexa de hidrocarbonetos com quantidade bastante significativa de isômeros, além destes, apresenta compostos contendo nitrogênio, oxigênio e enxofre,

*e-mail: rosangela.j@globo.com que dificultam as etapas de extração, isolamento e caracterização dos compostos. ${ }^{2,5}$

Os grandes progressos na instrumentação analítica nos últimos anos e o desenvolvimento de técnicas de extração mais robustas possibilitaram a detecção e identificação de ácidos naftênicos provenientes de petróleo.

Entre as principais técnicas de extração aplicáveis ao estudo de derivados do petróleo pode-se citar a extração líquido-líquido (clássica) (LLE - liquid-liquid extraction), a extração em fase sólida (SPE - solid phase extraction) e a cromatografia líquida preparativa de adsorção e de troca iônica. ${ }^{2,5,7}$

A cromatografia gasosa acoplada à espectrometria de massas (GC/MS - gas chromatography/mass spectrometry) é uma técnica analítica amplamente utilizada para amostras petroquímicas, embora ainda sejam necessárias etapas de isolamento e derivatização dos compostos mais polares. , $5,7-11^{2}$ Contudo, nem sempre ocorre a separação individual dos componentes e, frequentemente, os cromatogramas apresentam as chamadas misturas complexas não resolvidas (UCM - unresolved complex mixtures), as quais tornam a análise muito difícil. Além disso, a extensa fragmentação dos interferentes acíclicos, comuns nos derivados de petróleo e misturas técnicas comerciais de ácidos naftênicos, no espectrômetro de massas, fornece informações limitadas sobre a estrutura e massa molecular dos AN.

A cromatografia líquida acoplada à espectrometria de massa (LCMS - liquid chromatography-mass spectrometry) permite a análise direta e a confirmação dos ácidos naftênicos. Existem vários métodos para a sua determinação por MS, baseados em diferentes fontes de ionização, tais como, fast atom bombardment (FAB), ion spray (IS), thermospray (TS), liquid secondary ion (LSI), electrospray (ESI) e atmospheric pressure chemical ionization (APCI).,5,12-14

A cromatografia gasosa bidimensional abrangente $(\mathrm{GC} \times \mathrm{GC}$ - comprehensive two-dimensional gas chromatography) é uma ferramenta analítica que vem sendo aplicada com sucesso a amostras complexas como, por exemplo, as petroquímicas. ${ }^{15-17}$ Podem-se citar como vantagens dessa técnica o aumento da capacidade de picos em função do espaço bidimensional de separação e na estruturação espacial dos compostos de acordo com a classe química. 
Nos últimos anos, a técnica espectrometria de massas com ressonância ciclotron iônica e transformada de Fourier (FT-ICR MS - Fourier transform-ion cyclotron resonance mass spectrometry) tem sido utilizada para a identificação de ácidos naftênicos em óleo cru..$^{5,11,18,19}$

O estudo dos ácidos naftênicos é relevante, tanto do ponto de vista analítico, como da tecnologia de refino do petróleo, pois, além de apresentar concentrações baixíssimas, pertence a uma matriz complexa de grande interesse econômico.

Neste artigo de revisão são abordadas as estruturas, propriedades, usos, corrosão, toxidez e diferentes metodologias analíticas aplicadas à extração, derivatização, detecção e quantificação de ácidos naftênicos presentes em amostras de petróleo.

\section{ÁCIDOS NAFTÊNICOS}

Os ácidos naftênicos foram descobertos há cerca de 100 anos e o termo é comumente usado na indústria do petróleo para identificar todos os ácidos carboxílicos presentes na amostra. ${ }^{2,5,17}$

Os ácidos naftênicos são formados no óleo cru por degradação bacteriana. As bactérias atacam a cadeia parafínica formando, preferencialmente, compostos com anéis naftênicos e aromáticos de cadeia mais curta. A ação da biodegradação é citada como responsável pelo aumento dos compostos ácidos e dos compostos contendo nitrogênio e, pela redução em compostos parafínicos. ${ }^{19,20}$ Eles são constituintes naturais do betume, do petróleo e de várias frações de destilado dessa matriz, sendo que a concentração dos ácidos naftênicos aumenta nos cortes com ponto de ebulição entre 250 e $400^{\circ} \mathrm{C}$. ${ }^{2,5,21-23}$ Além do petróleo e do betume, os ácidos naftênicos são encontrados nas águas residuárias, resultantes do processo de extração do betume de óleos, como no caso das areias de Atabasca, próximo ao Forte McMurray em Alberta, Canadá. ${ }^{24-28}$

A estrutura fundamental dos ácidos naftênicos foi determinada na década de 1960, segundo Brient e colaboradores. ${ }^{4}$ De acordo com os autores, até 1955 somente dois ácidos naftênicos com 10 átomos de carbono haviam sido identificados. Desde então, devido às pesquisas desenvolvidas utilizando várias ferramentas analíticas, foi possível obter dados sobre a estrutura desse material, bem como descobrir que os processos de purificação, durante o processamento do petróleo, degradam os AN. ${ }^{2-4}$

\section{Estrutura dos ácidos naftênicos}

Os ácidos naftênicos são um grupo diverso de ácidos saturados, predominantemente monocarboxílicos, sendo diferenciados pela cadeia hidrocarbônica. São compostos constituídos de um ou mais anéis fundidos de ciclopentano e/ou ciclo-hexano, os quais podem ser alquilados. Os ácidos acíclicos também fazem parte desse grupo de compostos. ${ }^{4,22,29,30}$ Outros ácidos, tais como, dicarboxílicos ou contendo anéis aromáticos, podem estar presentes em pequena quantidade. ${ }^{4,26,31}$ Os ácidos naftênicos seguem, predominantemente, a estrutura representada na Figura 1(A), na qual m representa o número de grupos $\left(-\mathrm{CH}_{2}-\right)$, n o número de anéis e $\mathrm{R}$ a cadeia alquílica.

Os ácidos naftênicos também são genericamente representados pela fórmula $\mathrm{C}_{\mathrm{n}} \mathrm{H}_{2 \mathrm{n}-\mathrm{z}} \mathrm{O}_{2}$, onde $\mathrm{n}$ indica o número de carbonos e $\mathrm{z}$ representa o número de átomos de hidrogênio perdidos na ciclização da estrutura (especificando as séries homólogas). O z é igual a zero para acíclicos saturados, 2 em monocíclicos, 4 em bicíclicos, 6 em tricíclicos, 8 em tetracíclicos e assim sucessivamente. A massa molecular dos ácidos naftênicos varia de 14 unidades de massa $\left(\mathrm{CH}_{2}\right)$ entre as séries n e de 2 unidades $(2 \mathrm{H})$ entre as séries z. ${ }^{2,4,5,32}$ As estruturas típicas de alguns homólogos dos ácidos naftênicos estão mostradas na Figura 1(B) e Tabela 1. A Figura 1 mostra a estrutura para os

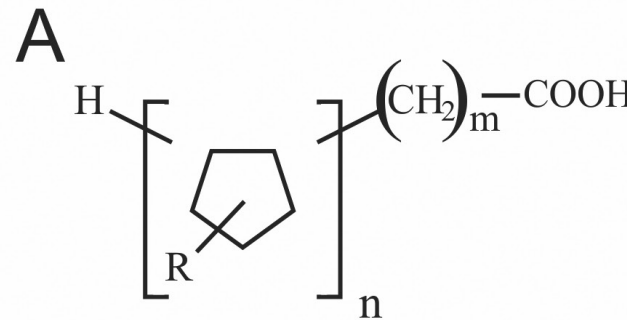

B


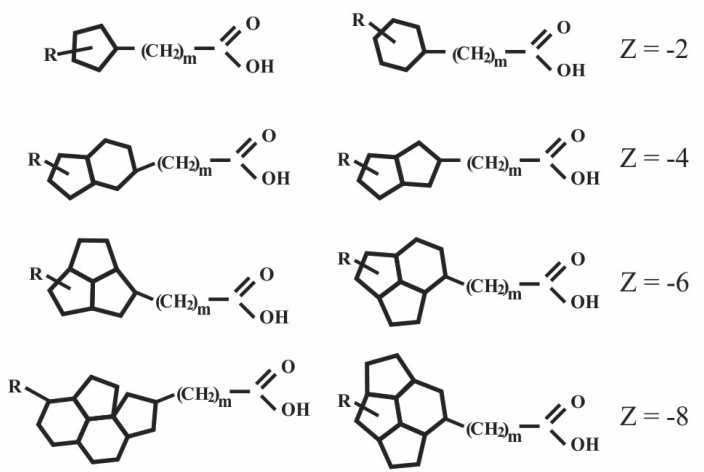

Figura 1. Estruturas representando ácidos naftênicos: (A) estrutura geral de ácidos naftênicos e (B) exemplos de estruturas de ácidos naftênicos com $z=0,2,4,6$ e 8

ácidos naftênicos na forma de anel- $\left(\mathrm{CH}_{2}\right)_{\mathrm{m}} \mathrm{CO}_{2} \mathrm{H}$, contudo alguns artigos preferem considerar como naftênicos apenas os ácidos com $\mathrm{m}=0$, ou seja, com o grupo COOH ligado diretamente ao anel. . $2,30,33,34^{-3}$

Os ácidos naftênicos com número de carbonos entre 7 e 12 são principalmente monocíclicos. Os ácidos mais complexos contêm proporções maiores de anéis condensados. , $^{2,5,26}$

A preponderância dos ácidos monocarboxílicos tem sido registrada para ácidos naftênicos derivados de frações pesadas do petróleo. ${ }^{26}$

A semelhança na complexidade e composição dos compostos identificados como ácidos naftênicos é salientada por Headley e colaboradores, ${ }^{35} \mathrm{em}$ sua pesquisa com espectrometria de massas e ionização por eletronebulização no modo negativo. Os autores consideram que a massa representada em cada pico pode corresponder a vários, ou até centenas de ácidos.

Os ácidos naftênicos têm uma composição heterogênea; além de representarem um percentual muito pequeno nas matrizes petrolíferas, ao serem extraídos carregam outros compostos considerados impurezas e de difícil remoção.

Naturalmente, as impurezas encontradas na mesma fração dos ácidos naftênicos estão intimamente relacionadas à fonte geradora do petróleo. Entre essas impurezas estão os fenóis, mercaptanas e tiofenóis, que são responsáveis por algumas características do extrato ácido como, por exemplo, o odor, gerado pela presença de fenóis e compostos sulfurados. . $^{2,4,5,15,17}$

\section{Propriedades dos ácidos naftênicos}

Os ácidos naftênicos não destilados são muito escuros, entretanto quando destilados são tipicamente amarelo-claro com pequena variação para o âmbar. Esses ácidos são líquidos viscosos e seus índices de refração e densidade podem ser usados para distinguir ácidos naftênicos de outros compostos. A massa molecular média 
Tabela 1. Fórmula empírica e massas moleculares (M) dos ácidos naftênicos que têm a fórmula $\mathrm{C}_{\mathrm{n}} \mathrm{H}_{2 \mathrm{n}+\mathrm{Z}} \mathrm{O}_{2}$ com $n$ número de carbonos (17-25) e número $Z(0$ a 12 )

\begin{tabular}{|c|c|c|c|c|c|c|c|}
\hline \multirow{2}{*}{$\begin{array}{l}\text { Número de } \\
\text { carbonos }\end{array}$} & \multicolumn{7}{|c|}{ Número de Z } \\
\hline & 0 & -2 & -4 & -6 & -8 & -10 & -12 \\
\hline 17 & $\begin{array}{c}\mathrm{C}_{17} \mathrm{H}_{34} \mathrm{O}_{2}{ }^{\mathrm{a}} \\
270^{\mathrm{b}}\end{array}$ & $\begin{array}{c}\mathrm{C}_{17} \mathrm{H}_{32} \mathrm{O}_{2} \\
268\end{array}$ & $\begin{array}{c}\mathrm{C}_{17} \mathrm{H}_{30} \mathrm{O}_{2} \\
266\end{array}$ & $\begin{array}{c}\mathrm{C}_{17} \mathrm{H}_{28} \mathrm{O}_{2} \\
264\end{array}$ & $\begin{array}{c}\mathrm{C}_{17} \mathrm{H}_{26} \mathrm{O}_{2} \\
262\end{array}$ & $\begin{array}{c}\mathrm{C}_{17} \mathrm{H}_{24} \mathrm{O}_{2} \\
260\end{array}$ & $\begin{array}{c}\mathrm{C}_{17} \mathrm{H}_{22} \mathrm{O}_{2} \\
258\end{array}$ \\
\hline 18 & $\begin{array}{c}\mathrm{C}_{18} \mathrm{H}_{36} \mathrm{O}_{2} \\
284\end{array}$ & $\begin{array}{c}\mathrm{C}_{18} \mathrm{H}_{34} \mathrm{O}_{2} \\
282\end{array}$ & $\begin{array}{c}\mathrm{C}_{18} \mathrm{H}_{32} \mathrm{O}_{2} \\
280\end{array}$ & $\begin{array}{c}\mathrm{C}_{18} \mathrm{H}_{30} \mathrm{O}_{2} \\
278\end{array}$ & $\begin{array}{c}\mathrm{C}_{18} \mathrm{H}_{28} \mathrm{O}_{2} \\
276\end{array}$ & $\begin{array}{c}\mathrm{C}_{18} \mathrm{H}_{26} \mathrm{O}_{2} \\
274\end{array}$ & $\begin{array}{c}\mathrm{C}_{18} \mathrm{H}_{24} \mathrm{O}_{2} \\
272\end{array}$ \\
\hline 19 & $\begin{array}{c}\mathrm{C}_{19} \mathrm{H}_{38} \mathrm{O}_{2} \\
298\end{array}$ & $\begin{array}{c}\mathrm{C}_{18} \mathrm{H}_{36} \mathrm{O}_{2} \\
296\end{array}$ & $\begin{array}{c}\mathrm{C}_{18} \mathrm{H}_{34} \mathrm{O}_{2} \\
294\end{array}$ & $\begin{array}{c}\mathrm{C}_{18} \mathrm{H}_{32} \mathrm{O}_{2} \\
292\end{array}$ & $\begin{array}{c}\mathrm{C}_{18} \mathrm{H}_{30} \mathrm{O}_{2} \\
290\end{array}$ & $\begin{array}{c}\mathrm{C}_{18} \mathrm{H}_{28} \mathrm{O}_{2} \\
288\end{array}$ & $\begin{array}{c}\mathrm{C}_{18} \mathrm{H}_{26} \mathrm{O}_{2} \\
286\end{array}$ \\
\hline 20 & $\begin{array}{c}\mathrm{C}_{20} \mathrm{H}_{40} \mathrm{O}_{2} \\
312\end{array}$ & $\begin{array}{c}\mathrm{C}_{20} \mathrm{H}_{38} \mathrm{O}_{2} \\
310\end{array}$ & $\begin{array}{c}\mathrm{C}_{20} \mathrm{H}_{36} \mathrm{O}_{2} \\
308\end{array}$ & $\begin{array}{c}\mathrm{C}_{20} \mathrm{H}_{34} \mathrm{O}_{2} \\
306\end{array}$ & $\begin{array}{c}\mathrm{C}_{20} \mathrm{H}_{32} \mathrm{O}_{2} \\
304\end{array}$ & $\begin{array}{c}\mathrm{C}_{20} \mathrm{H}_{30} \mathrm{O}_{2} \\
302\end{array}$ & $\begin{array}{c}\mathrm{C}_{20} \mathrm{H}_{28} \mathrm{O}_{2} \\
300\end{array}$ \\
\hline 21 & $\begin{array}{c}\mathrm{C}_{21} \mathrm{H}_{42} \mathrm{O}_{2} \\
326\end{array}$ & $\begin{array}{c}\mathrm{C}_{21} \mathrm{H}_{40} \mathrm{O}_{2} \\
324\end{array}$ & $\begin{array}{c}\mathrm{C}_{21} \mathrm{H}_{38} \mathrm{O}_{2} \\
322\end{array}$ & $\begin{array}{c}\mathrm{C}_{21} \mathrm{H}_{36} \mathrm{O}_{2} \\
320\end{array}$ & $\begin{array}{c}\mathrm{C}_{21} \mathrm{H}_{34} \mathrm{O}_{2} \\
318\end{array}$ & $\begin{array}{c}\mathrm{C}_{21} \mathrm{H}_{32} \mathrm{O}_{2} \\
316\end{array}$ & $\begin{array}{c}\mathrm{C}_{21} \mathrm{H}_{30} \mathrm{O}_{2} \\
314\end{array}$ \\
\hline 22 & $\begin{array}{c}\mathrm{C}_{22} \mathrm{H}_{44} \mathrm{O}_{2} \\
340\end{array}$ & $\begin{array}{c}\mathrm{C}_{22} \mathrm{H}_{42} \mathrm{O}_{2} \\
338\end{array}$ & $\begin{array}{c}\mathrm{C}_{22} \mathrm{H}_{40} \mathrm{O}_{2} \\
336\end{array}$ & $\begin{array}{c}\mathrm{C}_{22} \mathrm{H}_{38} \mathrm{O}_{2} \\
334\end{array}$ & $\begin{array}{c}\mathrm{C}_{22} \mathrm{H}_{36} \mathrm{O}_{2} \\
332\end{array}$ & $\begin{array}{c}\mathrm{C}_{22} \mathrm{H}_{34} \mathrm{O}_{2} \\
330\end{array}$ & $\begin{array}{c}\mathrm{C}_{22} \mathrm{H}_{32} \mathrm{O}_{2} \\
328\end{array}$ \\
\hline 23 & $\begin{array}{c}\mathrm{C}_{23} \mathrm{H}_{46} \mathrm{O}_{2} \\
354\end{array}$ & $\begin{array}{c}\mathrm{C}_{23} \mathrm{H}_{44} \mathrm{O}_{2} \\
352\end{array}$ & $\begin{array}{c}\mathrm{C}_{23} \mathrm{H}_{42} \mathrm{O}_{2} \\
350\end{array}$ & $\begin{array}{c}\mathrm{C}_{23} \mathrm{H}_{40} \mathrm{O}_{2} \\
348\end{array}$ & $\begin{array}{c}\mathrm{C}_{23} \mathrm{H}_{38} \mathrm{O}_{2} \\
346\end{array}$ & $\begin{array}{c}\mathrm{C}_{23} \mathrm{H}_{36} \mathrm{O}_{2} \\
344\end{array}$ & $\begin{array}{c}\mathrm{C}_{23} \mathrm{H}_{34} \mathrm{O}_{2} \\
342\end{array}$ \\
\hline 24 & $\begin{array}{c}\mathrm{C}_{24} \mathrm{H}_{48} \mathrm{O}_{2} \\
368\end{array}$ & $\begin{array}{c}\mathrm{C}_{24} \mathrm{H}_{46} \mathrm{O}_{2} \\
366\end{array}$ & $\begin{array}{c}\mathrm{C}_{24} \mathrm{H}_{44} \mathrm{O}_{2} \\
364\end{array}$ & $\begin{array}{c}\mathrm{C}_{24} \mathrm{H}_{42} \mathrm{O}_{2} \\
362\end{array}$ & $\begin{array}{c}\mathrm{C}_{24} \mathrm{H}_{40} \mathrm{O}_{2} \\
360\end{array}$ & $\begin{array}{c}\mathrm{C}_{24} \mathrm{H}_{38} \mathrm{O}_{2} \\
358\end{array}$ & $\begin{array}{c}\mathrm{C}_{24} \mathrm{H}_{36} \mathrm{O}_{2} \\
356\end{array}$ \\
\hline 25 & $\mathrm{C}_{25} \mathrm{H}_{50} \mathrm{O}_{2}$ & $\mathrm{C}_{25} \mathrm{H}_{48} \mathrm{O}_{2}$ & $\mathrm{C}_{25} \mathrm{H}_{46} \mathrm{O}_{2}$ & $\mathrm{C}_{25} \mathrm{H}_{44} \mathrm{O}_{2}$ & $\mathrm{C}_{25} \mathrm{H}_{42} \mathrm{O}_{2}$ & $\mathrm{C}_{25} \mathrm{H}_{40} \mathrm{O}_{2}$ & $\mathrm{C}_{25} \mathrm{H}_{38} \mathrm{O}_{2}$ \\
\hline
\end{tabular}

${ }^{\mathrm{a}}$ Fórmula química; ${ }^{\mathrm{b}}$ massa do composto com número de carbono e número $\mathrm{Z}$ correspondente. Citado na ref. 5

dos ácidos naftênicos derivados de óleo diesel com grupo - $\mathrm{COOH}$ ligado diretamente ao anel é de 260 , e para aqueles com $\mathrm{m} \geq 4$ é de 243. Os ácidos com massas moleculares mais altas são extraídos de frações do refino de petróleo com ponto de ebulição mais elevado. ${ }^{2,4,5}$

$\mathrm{O}$ interesse nas propriedades químicas dos ácidos naftênicos e derivados origina-se na crescente coprodução de óleos crus e ácidos, porque esse grupo de compostos apresenta grande variedade de tamanho e estrutura. As moléculas menores dissolvem-se na fase aquosa ( $\mathrm{pH} \sim 5$ ) e as maiores, no óleo, enquanto os homólogos dissolvem na fase aquosa $(\mathrm{pH}>10) \cdot{ }^{34,36-38} \mathrm{~A}$ presença de sais alcalinos, junto com o $\mathrm{pH}$, deve ser responsável pelas sensíveis variações na estabilidade das emulsões de frações contendo ácidos naftênicos. ${ }^{39-42}$

Os ácidos naftênicos presentes em asfaltenos formam um sistema difícil de analisar por técnicas espectroscópicas, já que a banda de absorção registrada tem um valor comum à de compósito. ${ }^{43}$

As reações mais importantes para estes compostos são amidação, esterificação, formação de sais metálicos, reações com imidazolinas e outros derivativos. ${ }^{44}$ Essas propriedades são responsáveis pela importância científica e comercial desse material.

Os ácidos naftênicos e seus sais acumulam-se na interface água/ óleo, promovendo a estabilização de soluções coloidais..$^{36,38,40} \mathrm{~A}$ estabilização das emulsões água/óleo causa problemas na entrada e saída dos separadores. Os sais metálicos pouco solúveis em água, como os de $\mathrm{Ca}$ e $\mathrm{Mg}$, acumulam-se na interface, como nucleação, formando aglomerados de partículas, que são responsáveis por frequentes interrupções operacionais nos processos de separação. ${ }^{45}$

Peng e colaboradores ${ }^{46}$ encontraram baixos valores de coeficientes de adsorção em solos, para ácidos naftênicos com um anel, indicando pouca capacidade adsorvente do solo em relação aos ácidos.

A entalpia de diluição dos ácidos naftênicos em soluções de tolueno, em várias concentrações, é positiva, e decresce com o aumento da concentração de ácido. Isto indica que a interação do ácido naftênico com outro ácido naftênico é mais forte do que a interação destes com o solvente. A principal razão para isto pode ser o fato de que os ácidos naftênicos interagem entre si formando ligações de hidrogênio, e algumas destas ligações são quebradas durante o processo de diluição. ${ }^{47}$

\section{Principais usos dos ácidos naftênicos}

Os ácidos carboxílicos são possíveis metabólitos da ação bacteriana durante os processos de biodegradação, podendo ser usados como indicadores deste processo. ${ }^{48} \mathrm{~A}$ correlação entre ácidos naftênicos e níveis de biodegradação foi registrada por Meredith e colaboradores. ${ }^{49}$

Gallhardo, ${ }^{3}$ analisando 15 amostras de óleo cru do oeste da Venezuela, após metilação com diazometano e análise via cromatografia gasosa com detector de ionização em chama (GC-FID - gas chromatography - flame ionization detector) e GC/MS, concluiu que o teor em ácidos pode aumentar devido à biodegradação e incorporação de ácidos durante a migração. Ácidos triterpenoicos pentacíclicos com configuração $(17 \beta \mathrm{H}, 21 \beta \mathrm{H})$ podem ser usados como parâmetros de maturação de sedimentos e indicadores de migração do petróleo. ${ }^{15,50}$

Jaffé e Gallardo ${ }^{50}$ extraíram os ácidos triterpenoicos de óleo cru da Nigéria e da Indonésia. Após a etapa de amidação e análise, foram encontrados diasteroisômeros do carbono C-22 em uma variedade de amostras geológicas, mas não foram detectados homólogos de hopanos mais pesados, indicando sua provável solubilização no óleo durante a migração ou, ao longo da maturação na rocha, apontando a possibilidade de uso como marcadores geoquímicos. Os hopanos são compostos derivados de membranas celulares de organismos procarióticos, bactérias e algas azuis, tendo um papel importante em sua rigidez, sendo substituídos por esteróis em organismos eucarióticos. ${ }^{51}$

Dois terços dos ácidos naftênicos isolados são convertidos em sais metálicos. ${ }^{52}$ Esses sais têm várias aplicações: os sais metálicos de cobalto, cálcio e manganês são usados na oxidação e polimerização de óleos secantes e resinas, na conservação de solventes e na catálise em sistemas orgânicos. Os naftenatos de metais pesados promovem solidificação nos filmes de tintas e vernizes e apresentam também alta solubilidade em óleos secantes. Sais de cobre e zinco têm atividade fungicida, com aplicação na indústria da madeira. ${ }^{2,5,53}$ 
O efeito de naftenatos de sódio no transporte de água e nos processos de troca gasosa foi examinado em raízes e folhas de álamos, por Kamaluddin e Zwiazek, ${ }^{54}$ que concluíram que houve uma inibição metabólica causada pelos sais sódicos de ácidos naftênicos, manifestada na forma de redução de atividade de água nas raízes, trocas gasosas e crescimento das folhas.

Outras utilizações dos ácidos naftênicos estão associadas às amidas desses ácidos, as quais podem ser usadas como inibidoras de corrosão e como antimicrobianas. ${ }^{2,5}$

\section{Toxicidade dos ácidos naftênicos}

A toxicidade dos ácidos naftênicos é associada, frequentemente, com sua característica surfactante e com a concentração desses ácidos. ${ }^{2,4,5,27,31,55,56}$

Derivados de ácidos naftênicos solúveis em água são responsáveis por reduzir a qualidade da água de rejeito no processo de extração do betume em Atabasca. ${ }^{45}$ Esses ácidos naftênicos têm sido citados, em vários trabalhos, como tóxicos para peixes, animais e plantas, ${ }^{55-58}$ embora não exista um método de rotina para identificar ou isolar os componentes específicos responsáveis pela toxicidade. A ausência de um método de rotina deve-se à complexidade da mistura, assim como pela ocorrência conjunta de outros grupos de substâncias, os quais também podem exercer efeito toxicológico e/ou ecológico. ${ }^{59-65}$ Amostras de água de vários mesocosmos revelaram efeito ecológico, estatisticamente significativo, em experimentos com comunidades de fitoplancton e zooplancton. ${ }^{66,67}$

Segundo Clemente e colaboradores,${ }^{68}$ a mistura complexa de ácidos naftênicos mostrou-se tóxica para várias formas de vida aquática. Esses autores registraram, ainda, a redução do efeito tóxico com a biodegradação por culturas aeróbicas, tanto em ambiente natural como em laboratório. Experimentos realizados para acompanhar a biodegradação de duas amostras comerciais de ácidos naftênicos demonstraram a redução da concentração de ácidos de 100 para 10 $\mathrm{mg} \mathrm{L}^{-1}$, resultando numa redução de toxicidade. ${ }^{69}$

Óleos brutos de petróleo normalmente contêm ácidos naftênicos em quantidades de até $4 \%$ em peso.

\section{Corrosão naftênica}

O mecanismo aceito para a corrosão naftênica pode ser expresso pelas Equações 1-3:

$$
\begin{gathered}
\mathrm{Fe}+2 \mathrm{RCOOH} \rightarrow \mathrm{Fe}(\mathrm{RCOO})_{2}+\mathrm{H}_{2} \\
\mathrm{Fe}+\mathrm{H}_{2} \mathrm{~S} \rightarrow \mathrm{FeS}+\mathrm{H}_{2} \\
\mathrm{Fe}(\mathrm{RCOO})_{2}+\mathrm{H}_{2} \mathrm{~S} \rightarrow \mathrm{FeS}+2 \mathrm{RCOOH}
\end{gathered}
$$

Este mecanismo pode ser resumido através da Figura 2..$^{70,71}$

Independentemente da fonte, a presença de ácidos nos óleos causa corrosão nos equipamentos de refino, sendo a determinação titulométrica do número de acidez total (TAN - total acid number) o procedimento mais comum para a avaliação da corrosividade. Essa medida indica a possibilidade de corrosão, mas é insuficiente do ponto de vista quantitativo, porque há óleos pouco corrosivos com número de acidez elevado, assim como o inverso, indicando que a corrosão depende da presença e da natureza de um determinado grupo de ácidos, cuja concentração não é explicitada pelo TAN..$^{71}$

Parte da corrosão nas unidades de refinaria é um problema atribuído aos ácidos naftênicos. Embora o mecanismo de ataque da superfície metálica por esse grupo de ácidos não seja suficientemente conhecido, a literatura registra a reação desses ácidos com o ferro, formando naftenatos de ferro. Estes sais são solúveis no óleo e dessorvem facilmente da superfície metálica, expondo o metal a

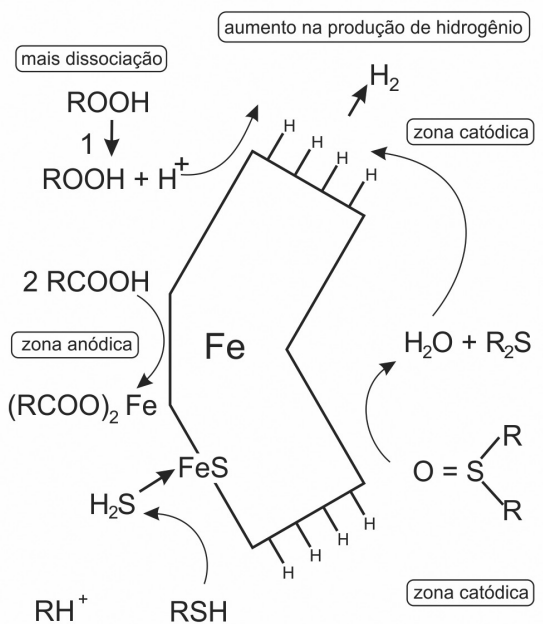

Figura 2. Provável mecanismo de ativação elou passivação da corrosão naftênica

novo ataque ácido. Os naftenatos de ferro podem reagir com ácido sulfídrico, formando sulfeto de ferro e regenerando o ácido, o que causa corrosão adicional, originando um ciclo de processos interligados. ${ }^{2,3,72,73} \mathrm{O}$ mecanismo do processo de corrosão, devido aos ácidos naftênicos, é uma questão de destaque a ser aprofundada na área de ciência de materiais. ${ }^{70,73}$

A resistência à corrosão-erosão causada pela presença de produtos naftênicos foi avaliada em aço-carbono, aço-carbono aluminizado e aço-carbono com molibdênio. ${ }^{74}$ Os resultados desse trabalho indicaram que o aumento da velocidade de fluxo e/ou da temperatura experimental afeta de modo significativo a corrosão-erosão por ácidos naftênicos, o que pode ser atribuído à acelerada transferência de massa do material resultante da corrosão, bem como por seu rápido afastamento da superfície metálica. Além disso, a resistência à corrosão-erosão naftênica nos materiais aço-carbono contendo alumínio e/ou molibdênio foi mais alta do que no aço-carbono.

A corrosão e a corrosão-erosão naftênica vêm sendo investigadas por Wu e colaboradores,${ }^{74}$ através da avaliação da adição de molibdênio em aços inoxidáveis, com o propósito de aumentar a resistência a esses processos agressivos. Nesses trabalhos ${ }^{6,74}$ foram realizados ensaios com a duração de 700 dias, revelando a efetiva proteção dos revestimentos ao substrato, aço-carbono, por longo tempo de exposição em ambiente de refinaria. Os mesmos autores reportaram que a resistência à corrosão e à corrosão-erosão naftênica é favorecida, porque metais como $\mathrm{Cr}, \mathrm{Ni}, \mathrm{Mn}$, Mo e seus íons têm menor afinidade do que o $\mathrm{Fe}$ ou o $\mathrm{Fe}^{2+}$ com $\mathrm{RCOO}^{-}$. Portanto, a presença destes elementos conduz à formação de filmes protetores na superfície do aço, diminuindo a área de $\mathrm{Fe}$ exposta e retardando enormemente a ligação entre o Fe e RCOO-

\section{Relação entre o teor de enxofre no combustível e a corrosão naftênica}

A medida da quantidade total de enxofre nos combustíveis nada informa sobre sua reatividade; no entanto, os compostos sulfurados podem inibir, catalisar ou ser inertes à ação corrosiva naftênica do aço-carbono. ${ }^{75-79}$

A relação entre TAN, conteúdo de enxofre e atividade corrosiva tem sido tema de algumas pesquisas. ${ }^{25,80,81}$

A corrosão nas unidades de destilação da refinaria Salina Cruz (México), tanto à pressão atmosférica, quanto à pressão reduzida, foi estudada por Laredo e colaboradores..$^{82}$ De acordo com os resultados, a presença de ácidos naftênicos de baixo peso molecular, associada ao 
reduzido conteúdo de enxofre, pode estar na origem dos processos de corrosão. Contudo, os autores ressaltam a necessidade da avaliação de outros fatores, como o conteúdo de sais e/ou a metalurgia do material do equipamento. $\mathrm{O}$ efeito dos compostos sulfurados na corrosão, relacionada com os ácidos naftênicos, envolve redução por prótons gerados no processo corrosivo. Quando o produto de redução é o $\mathrm{H}_{2} \mathrm{~S}$, há formação de uma camada protetora de $\mathrm{FeS}$, a qual previne do ataque naftênico. Porém, quando o produto de redução é a $\mathrm{H}_{2} \mathrm{O}$, a dissociação do ácido torna-se possível e intensifica a reação catódica, promovendo severa corrosão naftênica. ${ }^{73}$

A elucidação da estrutura (número de anéis e de carbonos e sua distribuição nas moléculas) dos ácidos naftênicos tem sido muito pesquisada, porque tanto a corrosividade naftênica como o efeito tóxico ambiental dependem do tipo e tamanho da estrutura destes ácidos. ${ }^{2,5,78,83}$

\section{Técnicas de extração e derivatização dos ácidos naftênicos}

A análise dos ácidos naftênicos necessita de um fracionamento prévio, que inclui várias etapas. A escolha dessas etapas, normalmente, depende das condições de trabalho disponíveis e da otimização das técnicas.

A natureza ácida do composto de interesse permite a remoção da matriz através de LLE utilizando soluções alcalinas ou amoniacais. Seifert e colaboradores ${ }^{84,85}$ fizeram uso exaustivo dessa técnica extrativa, necessitando de vários quilogramas de amostra e litros de solvente. Lo e colaboradores ${ }^{86}$ empregaram a LLE para extrair ácidos naftênicos da água do Lago Mildred; o pH das amostras foi ajustado para 12 com $\mathrm{NaOH}$ e os compostos básicos e neutros foram removidos por extração com diclorometano (DCM). A solução aquosa foi acidificada a $\mathrm{pH} 2$ com ácido sulfúrico $12 \mathrm{~mol} \mathrm{~L}^{-1}$. O precipitado, com a maioria dos ácidos naftênicos, foi removido com DCM.

Ácidos naftênicos foram retirados de óleos das minas de areia betuminosa, em Alberta, ${ }^{11,57,87-89}$ utilizando digestão com $\mathrm{NaOH}$ e água morna $\left(50-80{ }^{\circ} \mathrm{C}\right)$. Segundo Jivraj e colaboradores, ${ }^{90}$ para extrair os ácidos naftênicos do óleo da areia de Atabasca, as amostras foram centrifugadas ou filtradas para remoção do material particulado; após, o sobrenadante foi acidificado e extraído com DCM em água, na razão 1:2 (v/v). O extrato orgânico resultante foi evaporado até secura, reconstituído em água e submetido à ultracentrifugação, para separar moléculas de baixo peso molecular (AN) de moléculas de alto peso molecular (outros compostos). Rogers e colaboradores ${ }^{27}$ adaptaram a técnica extrativa de Jivraj e colaboradores ${ }^{91}$ para a extração dos ácidos naftênicos dos depósitos de águas residuárias resultantes dos processos de extração do betume do óleo das areias de Atabasca.

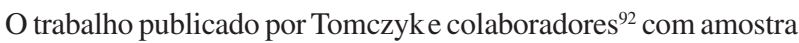
de óleo de San Joaquin (Califórnia) apresenta o tipo de distribuição de ácidos em amostras de óleo cru biodegradado (TAN = 5,19 mg KOH/g de óleo), uma versão modificada do método de Seifert e Howells. ${ }^{93}$ Nessa adaptação foram usados $45 \mathrm{~g}$ de amostra dissolvidos em $67 \mathrm{~g}$ de isopentano, seguida de dez extrações com uma solução alcalina a $1 \%$ (em massa) de $\mathrm{NaOH}$ em etanol/água a $70 \%$ (em volume) e por duas lavagens com etanol a 70\% (em volume). Após, o extrato foi centrifugado, sendo que a camada aquosa passou por decantação para separação de sólidos e acidificada (em banho de gelo). A solução acidificada foi extraída com éter etílico, lavada com água destilada, seca com sulfato de magnésio, filtrada e evaporada até secura. Como resultado foram encontrados $40 \%$ de compostos com caráter ácido, sendo que destes somente $10 \%$ continham dois átomos de oxigênio na estrutura (ácidos carboxílicos típicos). Os autores explicaram a presença dos componentes ácidos no óleo como decorrentes da biodegradação por micro-organismos.
A obtenção de extratos ácidos por LLE utilizando soluções alcalinas e amoniacal é um método amplamente registrado na literatura, embora utilize processos exaustivos de extração e com grande volume de solventes. A eficiência no isolamento pode ser prejudicada devido à formação de emulsões e coextração de impurezas ácidas, como fenóis e carbazóis. ${ }^{2,5}$

A extração cáustica é padrão na indústria, embora processos não cáusticos para recuperação dos ácidos naftênicos dos destilados do petróleo venham sendo empregados, mas não comercializados. Estes processos incluem o uso de amônia, trietilenoglicol, resina de troca iônica e zeólita aluminossilicato. ${ }^{94}$

A cromatografia em coluna aberta e a cromatografia líquida de alta eficiência (HPLC- high performance liquid chromatography) em fase normal, empregando a sílica como fase estacionária, são os métodos preparativos de amostras petroquímicas mais difundidos na literatura. Denomina-se análise SARA o isolamento que fornece frações de compostos saturados, aromáticos, resinas e asfaltenos, eluídos conforme sua solubilidade em solventes de polaridade crescente. ${ }^{95-97}$ Para o isolamento de compostos ácidos, o uso de sílica é limitado, uma vez que os grupos silanóis presentes na superfície da sílica podem promover a adsorção irreversível dos compostos polares. ${ }^{98-100}$ Como alternativa para aumentar os teores de recuperação dos compostos ácidos, há estudos que utilizaram a sílica impregnada com $\mathrm{KOH}^{101-103}$ ou modificada com grupos aminopropílicos e cianopropílicos. ${ }^{104-107}$

Os trabalhos desenvolvidos por Bourgund e colaboradores ${ }^{104,106}$ empregaram a separação por cromatografia líquida preparativa em fase normal com colunas ciano para obtenção de frações ácidas de petróleo. O fracionamento realizado com coluna ciano semipreparativa obteve melhor resolução na fração de ácidos carboxílicos saturados, a recuperação ficou em torno de $70 \%$ em peso. Estas frações foram analisadas por espectroscopia na região do infravermelho e cromatografia por permeação em gel, cujos resultados forneceram análises do tipo de grupo de compostos para as frações não polares, ácidos carboxílicos saturados, fenóis e ácidos polifuncionais.

Green e colaboradores ${ }^{108,109}$ desenvolveram metodologias por HPLC em fase normal, específica para ácidos carboxílicos, cujos objetivos foram rapidez de análise (menos de $1 \mathrm{~h}$ ) e seletividade de separação com a respectiva força ácida. Foi possível separar os compostos heteroatômicos do petróleo segundo o seu caráter ácido. A complexidade da fração de ácidos carboxílicos permitiu a identificação e quantificação de apenas quatro ácidos tricíclicos com valores de $m / z, 320,334$ e 376.

Métodos preparativos reprodutíveis, utilizando extração em fase sólida, para concentração de ácidos naftênicos e redução de interferentes presentes em amostras de água, bem como utilizando volumes relativamente pequenos de solvente, têm sido reportados. ${ }^{35}$ A SPE é um método eficiente nas recuperações dos AN. Há diversos estudos utilizando SPE no isolamento de AN em amostras de petróleo. ${ }^{23,34,98,105,110,111}$ As principais características desta técnica são a uniformidade da fase estacionária, baixo consumo de solventes e capacidade de separar compostos polares dos não polares.

Jones e colaboradores ${ }^{23}$ extraíram AN do petróleo empregando SPE e fase de amina quaternária, um trocador aniônico forte também denominado SAX, seguida de eluição com hexano para extrair os hidrocarbonetos apolares. Os compostos ácidos foram eluídos com a mistura éter dietílico:ácido fórmico $(98: 2 \mathrm{v} / \mathrm{v})$. O ácido naftênico tetracíclico 5 colânico $\left(\mathrm{C}_{28}\right)$ foi o que obteve maior recuperação (aproximadamente $90 \%$ ). Para os ácidos de cadeia linear a recuperação variou entre $98 \%$ para o ácido $\mathrm{C}_{14}$ e $37 \%$ para o $\mathrm{C}_{30}$.

Mazeas e Budzinski ${ }^{112}$ utilizaram colunas com alumina e sílica, sequencialmente, para separar hidrocarbonetos aromáticos de sedimentos marinhos e de petróleo, obtendo boa reprodutibilidade. 
Headley e colaboradores ${ }^{35}$ usaram um polímero, à base de poliestireno, na pré-concentração dos ácidos naftênicos em amostras de águas contaminadas, promovendo a eluição com acetonitrila.

Alguns autores têm utilizado a sílica como material adsorvente para cromatografia líquida preparativa ou em batelada para fracionar derivados de petróleo. ${ }^{105,113-115}$ A sílica modificada como, por exemplo, a aminopropilsílica, cuja aplicação é sugerida por Qian, ${ }^{105}$ também tem sido empregada com bons resultados.

Há vários autores que têm utilizado material adsortivo para fracionar matrizes combustíveis ou seus derivados..$^{12,14,84,85,102,105,116-119}$ Uma das alternativas é o uso de sílica modificada com $\mathrm{KOH}$, a qual foi utilizada por McCarthy e Duthie $\mathrm{e}^{53}$ e modificada por Schmitter. ${ }^{114}$ O material adsorvente é colocado em um sistema semelhante ao Soxhlet para obtenção de frações de diferentes polaridades. O sistema economiza solvente e tempo, além de minimizar a intervenção do operador.

São propostos vários materiais para retirar os ácidos naftênicos e outros compostos de sua matriz de origem, entre eles, as resinas de troca iônica. ${ }^{23,71,84,85,98,113,120,121}$ Gaikar e Maiti, ${ }^{113}$ citando outros autores, sugerem que é melhor utilizar técnicas adsortivas para separar analitos presentes em baixas concentrações nas amostras. Os mesmos autores, estudando a adsorção de ácidos naftênicos em três materiais, registraram baixa capacidade de adsorção para zeólita Na-X, moderada capacidade de adsorção para o poli(4-vinilpiridina) e para a bentonita, alta capacidade para resina de troca iônica. Em sequência, sugerem que a interação entre o soluto e o grupo amino da resina é do tipo ácido-base, a qual pode ser expressa pela sequência mostrada na Figura 3.

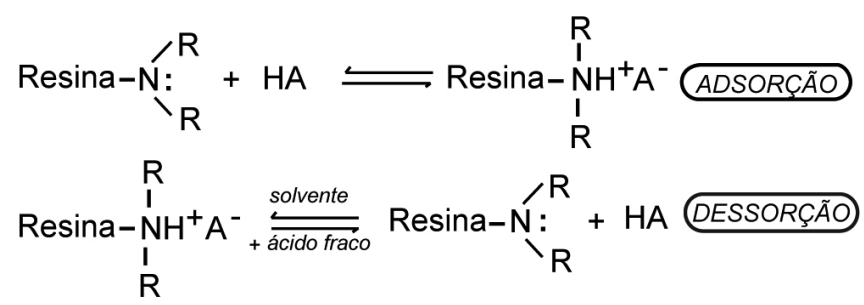

Figura 3. Reações envolvidas no processo de adsorção/dessorção na resina de troca iônica

Gaikar e Maiti ${ }^{113}$ concluíram que a capacidade de adsorção na resina se deve, provavelmente, à porosidade e acessibilidade do grupo funcional, sendo governada pela resistência difusional interna e pela dependência com a concentração.

Altgelt e Gouw, citados por Shimitter, ${ }^{114}$ acrescentaram à extração com resina de troca iônica executada por Jewel e colaboradores ${ }^{98} \mathrm{a}$ cromatografia por permeação em gel para separar os ácidos de fenóis, carbazóis e amidas, não retidos pela resina.

Seifert e colaboradores, ${ }^{84,85}$ utilizando resina de troca iônica fortemente básica e fracamente básica após a extração líquido-líquido, conseguiram pré-fracionar óleo cru da Califórnia e obter frações com conteúdo de ácido em torno de $1 \%$.

Jones e colaboradores ${ }^{23}$ registraram baixas recuperações para ácidos leves, fazendo uso de resina fracamente básica no processo de separação da fração ácida de petróleo, mas os mesmos resultados não são verificados para os ácidos de peso molecular médio e mais pesados.

Miwa $^{122}$ desenvolveu um método de extração e quantificação de ácidos baseado no HPLC com um processo de derivatização com 2-nitrofenil-hidrazida, em soluções aquosas. Clemente e colaboradores $^{69}$ adaptaram este método para monitorar a biodegradação de ácidos naftênicos por bactérias em laboratório.

A literatura registra a ausência de um método de rotina ou um mais recomendado para analisar ácidos naftênicos, provavelmente devido à complexidade da matriz e das misturas desses ácidos. ${ }^{94}$

\section{Técnicas de análise dos ácidos naftênicos}

Tradicionalmente, a área da química do petróleo emprega como técnicas de análise para as frações ácidas a espectroscopia de ressonância magnética nuclear de hidrogênio e carbono (NMR-H e NMR-C - nuclear magnetic resonance), infravermelho com transformada de Fourier (FT-IR - Fourier transform infrared) e MS. ${ }^{2,5,11,30,36,89,92,97,105,109,111,123-126}$

A FT-IR foi usada para a avaliação prévia da concentração de ácidos naftênicos em amostras de água contaminada pelo processo de extração do óleo da areia em Atabasca. Amostras de ácidos naftênicos comerciais foram preparadas para se obter a curva de calibração, sendo registradas as absorbâncias de $1743 \mathrm{~cm}^{-1}$ (monômeros) e 1706 $\mathrm{cm}^{-1}$ (dímeros). ${ }^{87-90}$

Yen e colaboradores, ${ }^{125}$ dispondo de 58 amostras de água contendo ácidos naftênicos, compararam os resultados obtidos por FT-IR e HPLC. Os ácidos ciclo-hexanobutírico, trans-1,4-pentilciclo-hexanocarboxílico, láurico, palmítico, esteárico e $5 \beta$-colânico foram utilizados como padrões. Concluíram que o método usando HPLC foi mais eficiente, pois a preparação da amostra foi mais rápida, com menores volumes de solvente e a automatização reduziu o tempo total de análise. Entretanto, devido à complexidade das amostras de ácidos naftênicos, muitos compostos derivatizados eluíram da coluna e foram registrados como picos não resolvidos.

A cromatografia líquida de alta eficiência associada a espectrômetro de massas tandem (HPLC-MS/MS - high performance liquid chromatography - tandem mass spectrometry) também é apresentada como técnica para análise de ácidos naftênicos. ${ }^{2,5,11}$ Wang e Kasperski ${ }^{14}$ desenvolveram um método para separar misturas de ácidos naftênicos de amostra aquosa proveniente do processo de extração de betume. Esse método também é indicado para análise quantitativa de alguns ácidos naftênicos individuais presentes na mistura. ${ }^{11}$ A HPLC associada a detectores de espalhamento de luz (ELSD - evaporative light scattering detector) e detector de arranjo de diodo (DAD-UV - diode array dection-ultraviolet) também já foi utilizada com a finalidade de comparar diferentes métodos de extração de ácidos naftênicos contidos em amostras de óleos brutos. ${ }^{127}$

HPLC/TOF-MS é uma técnica adequada para a caracterização precisa de classes de compostos em amostras de petróleo bruto e águas, como ácidos naftênicos. Bataineh e colaboradores ${ }^{128}$ estudaram a técnica de HPLC/QTOF-MS (high performance liquid chromatography/quadrupole time-of-flight mass spectrometry) que combina alta especificidade e sensibilidade, capacidade quantitativa e a habilidade de detectar novos produtos de transformação, e novas informações estruturais dos isômeros de AN.

Uma variedade de métodos espectrométricos tem sido utilizada como principal ferramenta na obtenção de dados sobre a estrutura de ácidos naftênicos. ${ }^{5,11,84,85,94}$ Os métodos de ionização incluem impacto eletrônico, ${ }^{15,23,29,84,85}$ bombardeamento atômico rápido, ${ }^{22}$ ionização química, ${ }^{30,126}$ ionização química à pressão atmosférica, ${ }^{105}$ ionização/ dessorção da matriz assistida a laser, ${ }^{125}$ ionização de campo $^{117} \mathrm{e}$ ionização por eletronebulização. ${ }^{86,94}$

A literatura cita os métodos suaves de ionização, ou a geração de compostos estáveis à ionização, para que sejam obtidos resultados capazes de fornecer informações elucidativas a respeito dos ácidos naftênicos. Os resultados obtidos por Holowenko e colaboradores ${ }^{88}$ utilizando GC/MS na análise de t-BDMS (terc-butildimetilsilil) derivados de ácidos naftênicos, são semelhantes aos de Lo e colaboradores ${ }^{86} \mathrm{com}$ ionização por eletronebulização.

Entre as técnicas utilizadas para a análise de ácidos naftênicos, 
assim como para outras classes de constituintes de óleos crus, a cromatografia em fase gasosa (GC - gas chromatography) aparece como a técnica mais citada..$^{2,5,8,10,11,23,94,113}$ Apesar do desenvolvimento da GC e de novos detectores, a composição heterogênea dos ácidos naftênicos dificulta a sua caracterização por técnicas cromatográficas comuns, pois pequenas quantidades de uma grande variedade de ácidos são encontradas em qualquer amostra extraída de petróleo e derivados. ${ }^{2,5,11} \mathrm{O}$ acoplamento da cromatografia gasosa com espectrometria de massas (GC/MS) permite a identificação e a quantificação destes compostos, através da combinação dos tempos de retenção e espectros de massas. $2,5,10,15,23,34,129-130$

Vários autores têm utilizado essa ferramenta analítica (GC) para analisar os ácidos naftênicos. . $5,10,12,15,23,33,126-132$ Aplicando a GC em amostras de óleos biodegradados e não biodegradados do Mar do Norte, Jones e colaboradores ${ }^{23}$ encontraram os ácidos $n$-parafínicos com 16 e 18 átomos de carbono na molécula nos óleos não biodegradados e não os encontraram nos óleos biodegradados.

Qian e colaboradores ${ }^{105}$ empregaram a espectrometria de massas de alta resolução para avaliar a fração ácida obtida por SPE de óleos crus. Foi determinada a presença de ácidos com n variando de 15 até 55 e $\mathrm{Z}$ entre - 2 e -12 (um e seis anéis naftênicos), além de ácidos aromáticos com até 3 anéis e estruturas contendo mais de dois átomos de oxigênio. Estes resultados revelam a complexidade da fração ácida de óleos crus e sugerem a presença majoritária de fenóis e outros ácidos carboxílicos.

Até o presente momento, a GC/MS é a técnica responsável pelo maior número de informações na tentativa de caracterizar as estruturas dos AN. 2,5,10,11,29,133-135 Contudo, a ionização por impacto eletrônico (EI - electron impact) apresenta como desvantagem a fragmentação excessiva dos compostos, gerando espectros complexos que fornecem informações limitadas sobre estrutura e massa molecular destes ácidos. Os métodos de análise que usam a etapa de metilação, para obter ésteres dos ácidos carboxílicos, geram derivados de elevadas massas moleculares, os quais produzem íons radicais muito instáveis, conduzindo à perda de informação quanto à massa molecular do composto. ${ }^{23}$

St. John e colaboradore ${ }^{29}$ desenvolveram um método simples para derivatizar AN em seus respectivos ésteres ( $t$-BDMS) para análise por GC/MS com ionização por impacto de elétrons, assim obtendo espectros de massas de mais fácil interpretação. Os ésteres de $t$-BDMS são obtidos pela reação do derivatizante $N$-metil- $N$-( $t$-butildimetilsilil) trifluoracetamida, abreviado por MTBDSTFA, com o hidrogênio ácido dos AN. A Figura 4 descreve o caminho de fragmentação dos ésteres de $t$-BDMS. Esta estratégia de derivatização é ainda hoje muito empregada, pois diminui a extensa fragmentação, quando comparada

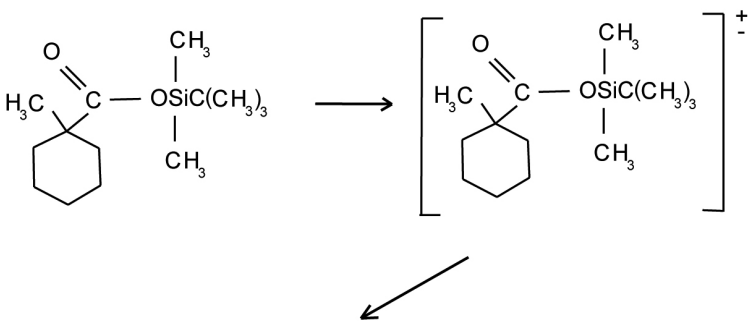

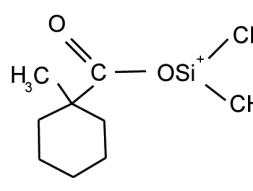

[M - 57]
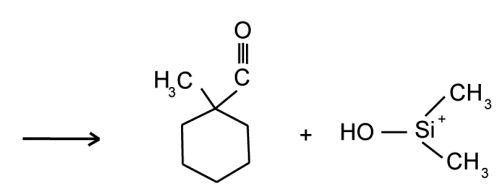

$[\mathrm{m} / \mathrm{z}=75$
Figura 4. Esquema de fragmentação para os íons predominantes dos derivados t-BDMS dos AN descrito por St. John e colaboradores ${ }^{29}$ a outros ésteres. O MTBDSTFA produz fragmentos característicos, cujo pico base predominante é o $\left[\mathrm{M}-\mathrm{C}_{4} \mathrm{H}_{9}\right]^{+}$, ou seja, $[\mathrm{M}-57]^{+} \mathrm{e}$ o íon $m / z$ 75. Estes íons são muito estáveis e permitem identificar a família de AN através de n, z e fórmula molecular. A Figura 5 ilustra o espectro de massa típico para um AN derivatizado com MTBDSTFA.

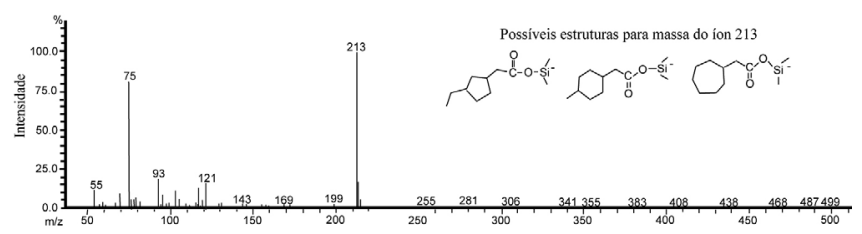

Figura 5. Espectro de massas para estruturas dos derivados t-BDMS de AN monocíclicas $(Z=-2)$, com 9 átomos de carbono e massa do íon 213

Após a análise via GC/MS, St. John e colaboradore ${ }^{29}$ encontraram que o perfil dos íons obtidos era similar ao encontrado por Dzidic e colaboradores, ${ }^{30}$ que empregaram o método de ionização branda (ionização química com fluoreto).

Clemente e Fedorak ${ }^{129}$ avaliaram o método de St. John e colaboradores ${ }^{29}$ detalhadamente, usando 6 ácidos monocarboxílicos puros e 5 extratos de AN provenientes de amostras de águas residuais e areias betuminosas. Os autores consideraram os efeitos dos isótopos naturais $\left(\mathrm{C}^{13}, \mathrm{Si}^{29} \mathrm{e} \mathrm{Si}^{30}\right)$ e forneceram uma expressão para corrigir os dados de massa espectral para estes isótopos. Além disto, salientaram na tabela de correlação de n, z e fórmula $\mathrm{C}_{n} \mathrm{H}_{2 n+\mathrm{Z}} \mathrm{O}_{2}$, proposta por St. John e colaboradores, ${ }^{29}$ algumas massas que representavam estruturas meramente teóricas.

Vaz de Campos e colaboradore ${ }^{10}$ empregaram a LLE, seguida de SPE com resina de troca iônica (Amberlyst A-27) e dessorção em ultrassom para isolar a fração ácida do gás óleo pesado de petróleo Marlim (Bacia de Campos, Rio de Janeiro, Brasil), derivatizadas com MTBDSTFA. As amostras foram analisadas por GC/MS utilizando o modo SIM (massa do ácido + 57). Os resultados indicaram a presença de ácidos alifáticos e AN que continham até quatro anéis saturados na estrutura molecular.

Dzidic e colaboradores ${ }^{30}$ desenvolveram uma técnica utilizando ionização química com trifluoreto de nitrogênio e espectrometria de massas (CI-MS - chemical ionization-mass spectrometry) para caracterizar ácidos naftênicos. Nesta técnica, somente um íon simples é formado ( $\left.\mathrm{RCOO}^{-}\right)$para cada ácido presente, reduzindo significativamente a complexidade do espectro. $\mathrm{O}$ íon representa a massa molecular do composto menos uma unidade. Porém, a CI-MS não é comumente usada na maioria dos laboratórios analíticos porque ainda implica em exaustivo investimento técnico. ${ }^{29}$

Barrow e colaboradores ${ }^{136}$ registraram resultados que possibilitam a caracterização de ácidos naftênicos em amostras de óleos crus, utilizando FT-ICR MS. Os autores justificam os bons resultados, através da técnica de ionização, a qual não gera fragmentação, reduzindo a complexidade do espectro de massas. Portanto, ocorre somente a detecção das espécies moleculares. A técnica pode ser usada diretamente no óleo cru e, portanto, não requer uma prévia separação ou derivatização. . $^{511,19}$

Recentes aplicações da técnica FT-ICR MS para análise de ácidos naftênicos mostraram ser fortemente dependente da escolha de solventes. ${ }^{11,19}$

Uma nova técnica de separação e análise espectrométrica foi desenvolvida por Gabryelski e Froese ${ }^{137}$ para caracterizar ácidos naftênicos de amostras comerciais e naturais. A técnica é denominada de ESI-FAIMS-MS e apresenta a ESI (electrospray ionization), FAI (high-field asymmetric wave-form ion mobility) acoplada com espectrometria de massas (quadrupolo) e espectrometria de massa sequencial (tempo de vôo). A separação de íons na fase gasosa é baseada na 
diferença relativa à mobilidade iônica em campos elétricos de baixa e alta intensidade. O mecanismo de separação depende mais da estrutura do íon (incluindo momento dipolar e polaridade) do que do seu tamanho. A quantificação e seletividade desta técnica são atribuídas à espectrometria de massas de baixa resolução (quadrupolo), enquanto a identificação é feita pela espectrometria de massas sequencial com detecção por tempo de vôo., ${ }^{5,11}$ A maior desvantagem da técnica está no elevado preço dos equipamentos envolvidos.

O surgimento da cromatografia bidimensional abrangente ( $\mathrm{GC} \times$ GC) no início de 1990 impulsionou enormemente o grau de separação cromatográfica para misturas complexas. ${ }^{138}$ Usando o espectrômetro de massas de tempo de vôo como técnica de detecção para o sistema GC $\times$ GC é possível obter mais de 500 espectros de massa por segundo, resolvendo de forma única os chamados "picos não resolvidos" ou UCM típicos de extratos de derivados de petróleos.,2,29,52,119

A combinação da cromatografia gasosa bidimensional abrangente com detector de espectrometria de massa por tempo de vôo (GC $\times$ GC/TOF-MS - comprehensive two-dimensional gas chromatography/ time-of-flight mass spectrometry) é uma poderosa ferramenta para a análise de misturas complexas, tais como ácidos naftênicos. ${ }^{5,11,139}$

Hao e colaboradores ${ }^{139}$ demonstraram a aplicação $\mathrm{GC} \times \mathrm{GC} /$ TOF-MS para caracterizar AN em duas misturas técnicas comerciais e amostras de areia betuminosa. Utilizaram cromatogramas bidimensionais reconstruídos para obter os espectros de massa deconvoluídos dos isômeros de AN. Nas misturas comerciais de AN foram encontrados ácidos acíclicos e cíclicos contendo um e dois anéis saturados. Contudo, a caracterização individual de cada AN presente nas misturas complexas estudadas pelo grupo não foi alcançada.

$\mathrm{O}$ trabalho de Shepherd e colaboradore ${ }^{12}$ avaliou a sensibilidade de vários agentes derivatizantes com o uso de GC × GC/TOF-MS para a caracterização de $\mathrm{AN}$ em misturas comerciais e amostras reais de petróleo. Uma série de agentes derivatizantes foi testada quanto à sensibilidade e em 10 padrões de AN. Embora a derivatização com BSTFA e MTBDSTFA tenha apresentado melhores recuperações quando se compara com agentes metilantes $\left(\mathrm{BF}_{3} / \mathrm{Metanol}\right)$, não houve evidências de uma derivatização seletiva para estrutura AN.

Rowland e colaboradores ${ }^{140}$ analisaram os metil ésteres derivados dos ácidos extraíveis da matéria orgânica (OSPW) (ácidos naftênicos)

Tabela 2. Técnicas de extração, identificação e quantificação dos ácidos naftênicos em diferentes matrizes

\begin{tabular}{|c|c|c|c|c|c|}
\hline Matriz & $\begin{array}{l}\text { Técnica de } \\
\text { extração }\end{array}$ & Derivatização & $\begin{array}{l}\text { Técnica de } \\
\text { detecção }\end{array}$ & Observações & Ref. \\
\hline - Óleo cru & $\begin{array}{l}\text {-Líquidos } \\
\text { iônicos }\end{array}$ & - & TAN & $\begin{array}{l}\text { Avaliação das variáveis do processo de extração para verificar } \\
\text { rendimento da extração com formação de liquido iônico na } \\
\text { reação }\end{array}$ & 5 \\
\hline $\begin{array}{l}\text { - Misturas comerciais } \\
\text { - Acros e Merichem } \\
\text { - Água de óleo de areia }\end{array}$ & -LLE & MTBSTFA & $\begin{array}{l}\text {-FT-IR } \\
\text {-GC/MS }\end{array}$ & $\begin{array}{l}\text { Realização de análise sensorial para detecção dos odores de } \\
\text { ácidos naftênicos }\end{array}$ & 7 \\
\hline - Tecido de peixe & -LLE & MTBSTFA & $-\mathrm{GC} / \mathrm{MS}$ & $\begin{array}{l}\text { Avaliação dos reagentes de derivatização MTBSTFA de dife- } \\
\text { rentes companhias }\end{array}$ & 8 \\
\hline - Água & -LLE & MTBSTFA & $\begin{array}{l}\text {-GC/MS } \\
\text {-FT-IR }\end{array}$ & $\begin{array}{l}\text { Comparação dos dois métodos para quantificação dos AN. Os } \\
\text { limites de detecção para GC/MS e FT-IR foram de } 0,1 \text { e } 1 \mathrm{mg} \\
\mathrm{L}^{-1} \text {, respectivamente }\end{array}$ & 9 \\
\hline $\begin{array}{l}\text { - Óleo pesado do } \\
\text { petróleo Marlin }\end{array}$ & $\begin{array}{l}-\mathrm{LLE} \\
-\mathrm{SPE}\end{array}$ & MTBDSTFA & $-\mathrm{GC} / \mathrm{MS}$ & $\begin{array}{l}\text { Os resultados indicaram a presença de ácidos alifáticos e AN } \\
\text { que continham até quatro anéis saturados na estrutura molecular }\end{array}$ & 10 \\
\hline $\begin{array}{l}\text { - Óleo cru } \\
\text { - Mistura Kodak e Sigma }\end{array}$ & -LLE & $\begin{array}{c}\text { BSTFA } \\
\text { MSTFA } \\
\text { MTBSTFA } \\
\text { TBDMSCl } \\
\mathrm{BF}_{3} \text { metanólico } \\
\end{array}$ & $-\mathrm{GC} \times \mathrm{GC} / \mathrm{TOF}-\mathrm{MS}$ & $\begin{array}{l}\text { Estudo de sensibilidade relacionado a diferentes agentes } \\
\text { silanizantes }\end{array}$ & 12 \\
\hline $\begin{array}{l}\text { - Óleo cru } \\
\text { - Depósito de naftenato } \\
\text { de cálcio }\end{array}$ & -LLE & - & $\begin{array}{l}\text {-ESI-MS } \\
\text {-APCI-MS }\end{array}$ & $\begin{array}{l}\text { Descreve diferentes métodos de extração de AN de óleo cru e } \\
\text { depósitos de naftenato de cálcio }\end{array}$ & 13 \\
\hline $\begin{array}{l}\text { - Misturas de ácidos } \\
\text { naftênicos }\end{array}$ & - & - & HPLC-MS/MS & Separação e quantificação de uma mistura de ácidos naftênicos & 14 \\
\hline - Óleo de areia & -LLE & - & FT-ICR MS & $\begin{array}{l}\text { Recentes aplicações da técnica para análise de ácidos naftênicos } \\
\text { mostraram ser fortemente dependente da escolha de solventes }\end{array}$ & 19 \\
\hline $\begin{array}{l}\text { - Ácidos naftênicos } \\
\text { sintéticos }\end{array}$ & - & - & $\begin{array}{c}\text {-NMR } \\
\text {-IR } \\
\text {-Análise elementar } \\
\text {-Calorímetro } \\
\end{array}$ & Esterificação de ácidos com catalisadores sintéticos & 124 \\
\hline - Rejeitos aquosos & $\begin{array}{l}\text {-LLE } \\
-\mathrm{SPE}\end{array}$ & - & HPLC/TOF-MS & $\begin{array}{l}\text { Capacidade quantitativa e habilidade de detectar novos produ- } \\
\text { tos de transformação e novas informações estruturais dos } \\
\text { isômeros de ácidos naftênicos (AN) }\end{array}$ & 128 \\
\hline - Tecido de peixe & $\begin{array}{l}\text {-LLE } \\
-\mathrm{SPE}\end{array}$ & MTBSTFA & $-\mathrm{GC} / \mathrm{MS}$ & $\begin{array}{l}\text { Os tecidos analisados foram coração, fígado, rins, brânquias e } \\
\text { músculos de peixe exposto em laboratório a ácidos naftênicos } \\
\text { Merichem }\end{array}$ & 133 \\
\hline $\begin{array}{l}\text { - Água proveniente do } \\
\text { óleo de areia }\end{array}$ & -LLE & MTBSTFA & $\begin{array}{c}\text {-GC/MS } \\
\text {-FT-IR } \\
\text {-Análise elementar } \\
\text { (C,H,N,S e O) } \\
\text {-ESI-FT-ICR MS }\end{array}$ & $\begin{array}{l}\text { Determinação de abundância e características de ácidos naf- } \\
\text { tênicos provenientes de diferentes fontes }\end{array}$ & 135 \\
\hline $\begin{array}{l}\text { - Misturas de ácidos } \\
\text { naftênicos } \\
\text { - Amostras de areias } \\
\text { betuminosas }\end{array}$ & -LLE & $\mathrm{BF}_{3} /$ metanol & $\mathrm{GC} \times \mathrm{GC} / \mathrm{TOF}-\mathrm{MS}$ & $\begin{array}{l}\text { Os autores utilizaram cromatogramas bidimensionais recon- } \\
\text { struídos para obter os espectros de massa deconvoluídos dos } \\
\text { isômeros de AN }\end{array}$ & 138 \\
\hline
\end{tabular}


utilizando a técnica GC $\times$ GC/TOF-MS. Os resultados mostraramm que a OSPW compreende um extensa série de ácidos tricíclicos diamantóides.

A Tabela 2 apresenta uma compilação de algumas técnicas de extração, identificação e quantificação dos ácidos naftênicos em diferentes matrizes.

\section{CONCLUSÕES}

As últimas descobertas de reservas de petróleo têm apresentado óleos com características mais ácidas. Esses óleos têm gerado algumas dificuldades para as refinarias e, consequentemente, a necessidade de se conhecer melhor a natureza dos compostos geradores de problemas e como melhor aproveitá-los. Há vários trabalhos que estudam a natureza, as técnicas de extração, identificação, biodegradação e corrosão e, também, apresentam as limitações das técnicas disponíveis para a caracterização dos ácidos naftênicos. Os estudos de identificação de ácidos presentes em amostras de petróleo e águas geradas no processo de extração de betume baseiam a caracterização no número de carbonos e número z; a dificuldade de identificação e quantificação origina-se na extração dos compostos presentes em baixa concentração na matriz e na grande quantidade de isômeros. Embora a caracterização ainda seja bastante difícil, estes estudos permitem afirmar que diferentes fontes de petróleo apresentam diferentes composições e estes resultados podem ajudar a solucionar problemas relacionados à corrosividade e toxidez. A literatura indica que ácidos de baixo peso molecular são mais suscetíveis à biodegradação que os de alto peso molecular.

Entre as principais técnicas de extração dos ácidos naftênicos pode-se citar a extração líquido-líquido e a extração em fase sólida, utilizando ampla gama de adsorventes para amostras aquosas, óleo bruto ou frações de petróleo. Entre as técnicas de caracterização mais usadas estão a CG/MS, FT-IR, NMR, HPLC sendo que nos últimos anos algumas técnicas mais recentes e sofisticadas como $\mathrm{GC} \times \mathrm{GC} /$ TOF-MS, MS/MS com ionização branda, HPLC/TOF-MS e FT-ICR MS vêm ganhando destaque pelos bons resultados apresentados.

Recentes descobertas de petróleo, com alto conteúdo de ácidos naftênicos e preocupações ambientais com as enormes quantidades destes ácidos sendo liberadas do processo de extração de areias petrolíferas, estimularão pesquisas para se entender melhor a composição, toxicidade, biodegradação e análise destas misturas complexas.

\section{AGRADECIMENTOS}

Ao apoio financeiro da Petrobras, CNPq (Conselho Nacional de Desenvolvimento Científico e Tecnológico) e FAPERGS (Fundação de Amparo à Pesquisa do Estado do Rio Grande do Sul).

\section{REFERÊNCIAS}

1. Fortuny, M.; Ramos, A. L. D.; Dariva, C.; Egues, S. M. S.; Santos, A. F.; Quim. Nova 2008, 31, 1553.

2. Vaz de Campos, M. C.; Tese de Doutorado, Universidade Federal do Rio Grande do Sul, Brasil, 2005

3. Gallardo, M. T.; Tésis de Maestria, Universidade Simón Bolívar, Venezuela, 1989.

4. Brient, J. A.; Wessner, P. J.; Doly. M. N. Em Encyclopedia of Chemical Technology; Kroschwitz, J. I., ed.; John Wiley \& Sons: New York, 1995.

5. Clement, S. J.; Fedorak, P. M.; Chemosphere 2005, 60, 585.

6. Wu, X. Q.; Jing, H. M.; Zheng, Y. G.; Yao, Z. M.; Ke, W.; Corros. Sci. 2004, 46, 1013.

7. Edge, K.; Barona, B.; Young, R. F.; Fedorak, P. M.; Wismer, W. V.; Chemosphere 2008, 81, 932

8. Young, R. F.; Coy, D. L.; Fedorak, P. M.; Anal. Methods 2010, $2,765$.
9. Scott, A. C.; Young, R. F.; Fedorak, P. M.; Chemosphere 2008, 73, 1258.

10. Vaz de Campos, M. C.; Oliveira, E. C.; Sanches Filho, P. J.; Piatnicki, C. M. S.; Caramão, E. B.; J. Chromatogr., A 2006, 1105, 95.

11. Headley, J. V.; Peru, K. M.; Barrow, M. P.; Mass Spectrom. Rev. 2009, $28,121$.

12. Shepherd, A. G.; Sorbie, K. S.; Thomson, G. B.; Westacott, R. E.; Energy Fuels 2010, 24, 4387.

13. Mohammed, M. A.; Sorbie, K. S.; Colloids Surf. A 2009, 349, 1.

14. Wang, X.; Kasperski, K. L; Anal. Methods 2010, 2, 1715.

15. Mühlen, C. V.; Oliveira, E. C.; Zini, C. A.; Caramão, E. B.; Marriot, P.; Energy Fuels 2010, 24, 3580.

16. Mühlen, C. V.; Zini, C. A.; Caramão, E. B.; Marriot, P.; Caramão, E. B.; Quim. Nova 2006, 29, 765.

17. Tran, T. C.; Logan, G. A.; Grosjean, E.; Ryan, D.; Marriot, P. J.; Geochim. Cosmochim. Acta 2010, 74, 6468.

18. Shi, Q.; Zhao, S.; Xu, Z.; Chung, K. H.; Zhang, Y.; Xu, C.; Energy Fuels 2010, 24, 4005 .

19. Headley, J. V.; Peru, K. M.; Barrow, M. P.; Derrick, P. J.; Anal. Chem. 2007, 79, 6222

20. Hunt, J. M.; Philp, R. P.; Kvenvolden, K. A.; Org. Geochem. 2002, 33, 1025.

21. Cyr, T. D.; Strausz, O. P.; Org. Geochem. 1984, 7, 127.

22. Fan, T. P.; Energy Fuels 1991, 5, 371

23. Jones, D. M.; Watson, J. S.; Meredith, W.; Chen, M.; Bennett, B.; Anal. Chem. 2001, 73, 703.

24. Gutzeit, J.; Mater. Perform. 1977, 16, 24.

25. Cooper, C. M.; Hydr. Proc. 1972, 51, 75.

26. Gutzeit, J.; Oil Gas J. 1976, 74, 156.

27. Rogers, V. V.; Liber, K.; MacKinnon, M. D.; Chemosphere 2002, 48, 519.

28. Strausz, O. P.; J. Am. Chem. Soc. 1988, 33, 264.

29. St. John, W. P.; Rughani, J.; Green, S. A.; McGinnis, G. D.; J. Chromatogr., A 1998, 807, 241.

30. Dizidic, I.; Somerville, A. C.; Raia, J. C.; Hart, H. V.; Anal. Chem. 1988, 60,1318 .

31. Lai, J. W. S.; Pinto, L. J.; Kiehlmann, E.; Bendell-Young, L. I.; Moore, M. M.; World Congress of the Society of Environmental Toxicology and Chemistry, Gulley, J., ed.; Vancouver, 1995.

32. Herman, D. C.; Fedorak, P. M.; Costerton, J. W.; Can. J. Microbiol. 1993, 39, 576

33. Seifert, W. K.; Teeter, R. M.; Anal. Chem. 1970, 42, 180.

34. Hsu, C. S.; Dechert, G. J.; Robbins, W. K.; Fukuda, E. K.; Energy Fuels 2000, 14, 217

35. Headley, J. V.; Peru, K. M.; McMartin, D, W.; Winkler, M.; J. AOAC Int. 2002, 85, 182 .

36. Acevedo, S.; Escobar, G.; Ranaudo, M. A.; Khazen, J.; Borges, B.; Pereira, J. C.; Méndez, B.; Energy Fuels 1999, 13, 333.

37. Rudin, J.; Wasan, D. T.; Colloids Surf. 1992, 68, 67.

38. Rudin, J.; Wasan, D. T.; Colloids Surf. 1992, 68, 81.

39. Mendez, Z.; Anton, R. E.; Salager, J. L.; J. Dispersion Sci. Technol. 1999, 20, 883 .

40. Strassner, J. E.; J. Pet. Technol. 1968, 20, 303.

41. Dickie, J. P.; Yen, T. F.; Anal. Chem. 1967, 39, 1847.

42. Strausz, O. P.; Mojelsky, T. W.; Lown, E. M.; Fuel 1992, 71, 1355.

43. Östlund, J-A.; Nydén, M.; Stilbs, P.; Energy Fuels 2004, 18, 531.

44. Whelan, J. K.; Farrington, J. W.; Organic Matter, Columbia University Press: New York, 1992

45. Havre, T.; Esse, M.-H.; Sjöblom, J.; Blokhus, A.; Colloid Polym. Sci. 2002, 280, 647

46. Peng, J.; Headley, J. V.; Barbour, S. L.; Can. Geotech. J. 2002, 30, 1419.

47. Zou, L.; Han, B.; Yan, H.; Kasperski, K. L.; Xu, Y.; Hepler, L. G.; J. Colloid Interface Sci. 1997, 190, 472

48. Behar, F. H.; Albrecht, P.; Org. Geochem. 1984, 6, 597. 
49. Meredith, W.; Kelland, S. J.; Jones, D. M.; Org. Geochem. 2000, 31, 1059.

50. Mckenzie, A. S.; Patience, R. L.; Yon, D. A.; Maxwell, J. R.; Geochim. Cosmochim. Acta 1982, 46, 783.

51. Jaffé, R.; Gallardo, M. T.; Org. Geochem. 1993, 20, 973.

52. Clemente, J. S.; Prasad, N. G. N.; MacKinnon, M. D.; Fedorak, P. M.; Chemosphere 2003, 50, 1265 .

53. McCarthy, R. D.; Duthie, A. H.; J. Lipid Res. 1962, 3, 117.

54. Kamaluddin, M.; Zwiazek, J. J.; Tree Physiol. 2002, 22, 1265.

55. Dokholyan, V. K.; Magomedov, K. J.; J. Ichthyol. 1983, 23, 125.

56. Rogers, V. V.; Wickstrom, M.; Liber, K.; MacKinnon, M. D.; Toxicol. Sci. 2002, 66, 347.

57. MacKinnon, M. D.; Boerger, H.; Water Pollut. Res. J. Can. 1986, 21, 496.

58. MacKinnon, M. D.; AOSTRA J. Res. 1989, 5, 109.

59. Leung, S. S.; MacKinnon, M. D.; Smith, R. E. H.; Aquat. Toxicol. 2003, $62,11$.

60. Hermann, D. C.; Fedorak, P. M.; MacKinnon, M. D.; Costerton, J. W.; Can. J. Microbiol. 1994, 40, 467.

61. Hammond, M. W.; Alexander, M.; Environ. Sci. Technol. 1972, 6, 732.

62. Dias, F. F.; Alexander, M.; Appl. Microbiol. 1971, 22, 1114.

63. Blakley, E. R.; Can. J. Microbiol. 1978, 24, 847.

64. Taylor, D. G.; Trudgill, P. W.; J. Bacteriol. 1978, 134, 401.

65. Blakley, E. R.; Papish, B.; Can. J. Microbiol. 1982, 28, 1324.

66. McCormick, J. K.; M. Sci. Thesis, University of Waterloo, Canadá, 2000.

67. Leung, S.; MacKinnon, M. D.; Smith, R. E. H.; Environ. Toxicol. Chem. 2001, 20, 1532 .

68. Clemente, J. S.; Yen, T. W.; Fedorak, P. M.; J. Environ. Eng. Sci. 2003, $2,177$.

69. Clemente, J. S.; MacKinnon, M. D.; Fedorak, P. M.; Environ. Sci. Technol. 2004, 38, 1009.

70. Yépez, O.; Fuel 2005, 84, 97

71. Alvisi, P. P.; Lins, V. F. C.; Eng. Failure Anal. 2011, 18, 1403.

72. March, J.; Advanced organic chemistry, McGraw-Hill: New York, 1977.

73. Tomczyk, N. A.; Winans, R. E.; Shinn, J. H.; Robinson, R. C.; Prepr.Am. Chem. Soc., Div. Pet. Chem. 1998, 3, 123.

74. Wu, X. Q.; Jing, H. M.; Zheng, Y. G.; Yao, Z. M.; Ke, W.; Wear 2004, $256,133$.

75. Kane, R. D.; Cayard, M. S.; Mater. Perform. 1999, 38, 48

76. Turnbull, A.; Slavcheva, E.; Shone, B.; Corrosion 1998, 54, 922.

77. Babaian-Kibala, E.; Craig, H. L.; Rusk, G. L.; Blanchard, K. V.; Rose, T. J.; Uehlein, B. L.; Quinter, R. C.; Summers, M. A.; Mater. Perform. 1993, 32, 50 .

78. Schütz, P.; Dissertação de Mestrado, Universidade Federal do Rio Grande do Sul, Brasil, 2009.

79. Okuno, I.; Latham, de W. R.; Haines, W. E.; Anal. Chem. 1967, 39, 1830.

80. Slavcheva, E.; Shone, B.; Turnbull, A.; Br. Corr. J. 1999, 34, 125.

81. Slavcheva, E.; Shone, B.; Turnbull, A.; Corrosion 1994, 54, 922.

82. Laredo, G. C.; López, C. R.; Álvarez, R. E.; Cano, J. L.; Fuel 2004, 83, 1689.

83. Koike, L.; Rebouças, L. M. C.; Reis, F. M. A.; Marsaioli, A. J.; Richnow, H. H.; Michaelis, W.; Org. Geochem. 1992, 18, 851.

84. Seifert, W. K.; Teeter, R. M.; Howells, G.; Cantow, M. J. R.; Anal. Chem. 1969, 41, 1638.

85. Seifert, W. K.; Teeter, R. M.; Anal. Chem. 1970, 42, 750.

86. Lo, C. C.; Brownlee, B. G.; Bunce, N. J.; Anal. Chem. 2003, 75, 6394.

87. Clemente, J. S.; MSc Thesis, University of Alberta, Canada, 2004

88. Holowenko, F. M.; Mackinnon, M. D.; Fedorak, P. M.; Water Res. 2002, 36, 2843.

89. Rudzinski, W. E.; Oehlers, L.; Zhang, Y.; Energy Fuels 2002, 16, 1178.

90. Jivraj, M. N.; MacKinnon, M. D.; Fung, B.; Technique report, Syncrude Res. Centre, Canada, 1997, p. 12

91. Jivraj, M. N.; MacKinnon, M. D.; Fung, B.; Naphthenic acid extraction and quantitative analysis with FTIR spectroscopy, Technical report, prepared for Syncrude Res. Centre, Canada, 1995.

92. Tomczyk, N. A.; Winans, R. E.; Shinn, J. H.; Robinson, R. C.; Energy Fuels 2001, 15, 1498.

93. Seifert, W. K.; Howells, W. G.; Geochim. Cosmochim. Acta 1981, 45, 783.

94. Headley, J. V.; McMartin, D. W.; J. Environ. Sci. Health 2004, 39, 1989.

95. Fuhr, B.; Bajac, B.; Blackmore, T.; Rahimi, P.; Energy Fuels 2007, 21, 1322 .

96. Kharrat, A. M.; Zacharia, J.; Cherian, V. J.; Anyatonwu, A.; Energy Fuels 2007, 21, 3618.

97. Fan, T.; Buckley, J. S.; Energy Fuels 2002, 16, 1571.

98. Jewel, D. M.; Weber, J. H.; Bunger, J. W.; Plancher, H.; Latham, D. R.; Anal. Chem. 1972, 44, 1391.

99. Radke, M.; Willsch, H.; Welte, D. H.; Anal. Chem. 1980, 52, 406.

100. Willsch, H.; Clegg, H.; Horsfield, B.; Radke, M.; Wilkes, H.; Anal. Chem. 1997, 69, 4203.

101. Nascimento, L. R.; Rebouças, L. M. C.; Koike, L.; Reis, F. A. M.; Soldan, A. L.; Cerqueira, J. R.; Marsaioli, A. J.; Org. Geochem. 1999, 30, 1175.

102. Caramão, E. B.; Gomes, L. M. F.; Bristoti, A.; Oliveira, M. D.; Lanças, F. M.; Fuel Sci. Technol. 1990, 8, 881.

103. Lanças, F. M.; Caramão, E. B.; Fuel Sci. Technol. 1996, 14, 417.

104. Borgund, A. E.; Erstad, K.; Barth, T.; J. Chromatogr., A 2007, 1149, 189.

105. Qian, K.; Robbins, W. K.; Hughey, C. A.; Cooper, H. J.; Rodgers, R. P.; Marshall, A. G.; Energy Fuels 2001, 15, 1505.

106. Borgund, A. E.; Erstad, K.; Barth, T.; Energy Fuels 2007, 21, 2816.

107. Miller, R.; Anal. Chem. 1982, 54, 1742.

108. Green, J. B.; Stierwalt, B. K.; Thomson, J. S.; Treese, C. A.; Anal. Chem. 1985, 57, 2207

109. Green, J. B.; J. Chromatogr., A 1986, 358, 53.

110. Wong, D. C.; van Compernolle, R.; Nowlin, J. G.; O’Neal, D. L.; Johnson, G. M.; Chemosphere 1996, 32, 1669.

111. Saab, J.; Mokbel, A. C.; Razzouk, A. C.; Ainous, N.; Zydowicz, N.; Jose, J.; Energy Fuels 2005, 19, 525.

112. Mazeas, L.; Budzinski, H.; J. Chromatogr., A 2001, 923, 165.

113. Gaikar, V. G.; Maiti, D.; React. Funct. Polym. 1996, 31, 155.

114. Schmitter, J. M.; Tese de Doutorado, Universidade Louis Pasteur, Strasbourg, 1978

115. Snyder, L. R.; Kirkland, J. J.; Introduction to Modern Liquid Chromatography, $2^{\text {nd }}$ ed., John Wiley \& Sons, Inc.: New York, 1979.

116. Tanaka, K.; Chikara, H.; Hu, W.; Hasebe, K.; J. Chromatogr., A 1999, $850,187$.

117. Qian, K.; Dechert, G. J.; Anal. Chem. 2002, 74, 3977.

118. Gallegos, E. J.; Anal. Chem. 1984, 56, 701.

119. Wu, J. C-S.; Sung, H-C.; Lin, Y-F.; Lin, S-L.; Sep. Purif. Technol. 2000, $21,145$.

120. Oliveira, E. C.; de Campos M. C. V.; Lopes, A. S.; Vale, M. G. R.; Caramão, E. B.; J. Chromatogr., A 2004, 1027, 171.

121. Teixeira, A. M. de F.; Dutra, K. C.; Muniz, C. H.; Teixeira, M. A. G.; Prepr.-Am. Chem. Soc. Div., Pet. Chem. 2002, 47, 1.

122. Miwa, H.; J. Chromatogr., A 2000, 881, 365.

123. Videla P. P.; Farwell, A. J.; Butler, B. J.; Dixon, D. G.; Water, Air, Soil Pollut. 2009, 197,107.

124. Azizov, A. H.; Amanullayeva, G. I.; Aliyeva, R. V.; Aliyev, B. M.; Bektashi, N. R.; Appl. Catal., A 2011, 396, 20.

125. Yen, T. W.; Marsh, W. P.; Mackinnon, M. D.; Fedorak, P. M.; J. Chromatogr., A 2004, 1033, 83.

126. Hur, M.; Yeo, I.; Kim, E.; No, M.; Koh, J.; Cho, Y. J.; Lee, J. W.; Kim, S.; Energy Fuels 2010, 24, 5521.

127. Borgund, A. E.; Erstad, K.; Barth, T.; Energy Fuels 2007, 21, 2816.

128. Bataineh, M.; Scott, A.C.; Fedorak, P. M.; Martin, J.W.; Anal. Chem. 2006, 78, 8354 .

129. Clemente, J. S.; Fedorak, P. M.; J. Chromatogr., A 2004, 1047, 117. 
130. Artok, L.; Su, Y.; Hirose, Y.; Hosokawa, M.; Murata, S.; Nomura, M.; Energy Fuels 1999, 13, 287.

131. Douglas, A. G.; Blumer, M.; Eglinton, G.; Douraghi-Zadeh, K.; Gas Chromatogr. 1970, 27, 1071.

132. Gruber, L. D. A.; Tese de Doutorado, Universidade Federal do Rio Grande do Sul, Brasil, 2009.

133. Young, R. F.; Michel, L. M.; Fedorak, P. M.; Ecotoxicol. Environ. Saf. 2011, 74, 889 .

134. Wang, Z.; Fingas, M.; Sergy, G.; Environ. Sci. Technol. 1994, $28,1733$.

135. Grewer, D. M.; Young, R. F.; Whittal, R. M.; Fedorak, P. M.; Sci. Total Environ. 2010, 408, 5997.
136. Barrow, M. P.; McDonnell, L. A.; Feng, X.; Walker, J.; Derrick, P. J.; Anal. Chem. 2003, 75, 860.

137. Gabryelski, W.; Froese, K. L.; Anal. Chem. 2003, 75, 4612.

138. Liu, Z.; Phillips, J.B.; J. Chromatogr. Sci. 1991, 29, 227.

139. Hao, C.; Headley, J. V.; Peru, K. M.; Frank, R.; Yang, P.; Solomon, K. R.; J. Chromatogr., A 2005, 1067, 277.

140. Rowland, S. J.; Scarlett, A. G.; Jones, D.; West, C. E.; Frank, R. A.; Environ. Sci. Technol. 2011, 45, 3154. 